\title{
Impacts of a tertiary treated municipal wastewater effluent on the carbon and nitrogen stable isotope signatures of two darter species (Etheostoma blennioides and $E$. caeruleum) in a small receiving environment
}

\author{
Chris S. Robinson ${ }^{\dagger},{ }^{*}$ Gerald R. Tetreault ${ }^{\dagger}$, Mark E. McMaster, Mark R. Servos ${ }^{\dagger}$ \\ ${ }^{\dagger}$ Department of Biology, University of Waterloo, 200 University Ave. W., Waterloo, ON N2L 3G1, \\ Canada \\ ${ }^{\ddagger}$ Ecosystem Health Assessment, Environment Canada, 867 Lakeshore Road, Burlington, ON L7R \\ 4A6, Canada
}

*corresponding author Gerald.Tetreault@ec.gc.ca 


\section{ABSTRACT}

This study contrasted the influence of tertiary treated municipal wastewater effluent (MWWE) exposure on the abundance, food selection (stomach contents), and carbon $\left(\delta^{13} \mathrm{C}\right.$ ) and nitrogen $\left(\delta^{15} \mathrm{~N}\right)$ stable isotope signatures of Rainbow Darter (Etheostoma caeruleum) and Greenside Darter (Etheostoma blennioides) in a small receiving stream in southern Ontario, Canada. Despite tertiary treatment resulting in relatively high effluent quality, there is continued concern for environmental degradation downstream of the effluent outfall because of the relatively small size of the receiving environment and recent studies that have indicated changes occurring in relative fish abundance and stable isotope signatures. In July and August of 2009 fish and benthic invertebrate communities were examined along with analysis of $\delta^{13} \mathrm{C}$ and $\delta^{15} \mathrm{~N}$ of the most common species to determine the effects of effluent exposure on the food web. Rainbow Darter increased in abundance and their $\delta^{15} \mathrm{~N}$ values were enriched immediately downstream of the effluent outfall throughout the summer (July and August). In contrast, while $\delta^{15} \mathrm{~N}$ of Greenside Darter followed a similar pattern in July, they were not enriched in August. The benthic community was changed immediately downstream of the outfall and the $\delta^{15} \mathrm{~N}$ of invertebrates was enriched, similar to that observed in Rainbow Darter. Stomach contents of the two darter species diverged the most in the summer possibly explaining some of the changes in $\delta^{13} \mathrm{C}$ and $\delta^{15} \mathrm{~N}$ among sites. It is possible that Greenside Darter fed on less enriched food downstream of the outfall, or fed outside of the effluent plume during the summer. Rainbow Darter may be able to exploit the changes in habitat and prey composition, resulting in differences in relative abundance of darters immediately downstream of the effluent outfall. 


\section{KEYWORDS}

municipal wastewater, aquatic food web, darter, stable isotopes, benthic invertebrates

\section{CAPSULE}

Exposure to tertiary treated municipal wastewater effluent caused changes to darter abundance and prey item selection indicating the potential for subtle impacts to aquatic ecosystem structure downstream of effluent outfalls.

\section{Introduction}

Municipal wastewater effluents (MWWEs) contain an array of compounds that can degrade aquatic environments. Nutrients, pharmaceuticals, and personal care products, natural and synthetic hormones, chlorides, inorganic chloramines and other industrial chemicals are all components of MWWEs that have been known to cause environmental impacts (Chambers et al., 1997; Environment Canada, 2001; Tetreault et al., 2011). With continued urbanization in Canada and the rest of the world, concern for the impacts of wastewater on the environment has continued to grow. Rapid population growth is occurring in southwestern Ontario, especially in the area west of Greater Toronto. The City of Guelph and its surrounding area (2011 population 126,000) are expecting a population increase of 38\% over the next twenty years (2011-2031; Grand River Conservation Authority, 2012), which may challenge the current wastewater infrastructure and threaten aquatic ecosystems. The Guelph Wastewater Treatment Plant releases tertiary treated effluent $\left(46,214 \mathrm{~m}^{3} / \mathrm{d}\right)$ into the Speed River, a small tributary of the Grand River (City of Guelph, 2011). Surface flow in the river is typically as low as $1.5-2 \mathrm{~m}^{3} / \mathrm{s}$ in the summer, reducing its ability to dilute and assimilate the nutrients and other compounds in the treated effluent (Grand River 
Conservation Authority, 2005; 2012). The anticipated population growth may increase the relative chemical and nutrient loads into the Speed River, creating concern that the assimilative capacity of the river could be exceeded, and degradation of the aquatic environment may occur. Prior to the commencement of treatment plant upgrades (19782008) and the construction of an upstream dam (1974), the river downstream suffered from extreme dissolved oxygen depression and overall poor environmental health (Gowda, 1983). A better understanding of the potential impacts are needed so that better decisions regarding wastewater treatment can be made in the future to protect vulnerable receiving environments.

Stable isotope analysis of carbon and nitrogen is a useful tool for understanding how anthropogenic nutrient inputs are incorporated by aquatic ecosystems (Peterson and Fry, 1987). Sources of pollution, such as MWWE and agriculture runoff, typically have different carbon and nitrogen isotopic signatures, enabling the detection of anthropogenic inputs (DeBruyn and Rasmussen, 2002; Loomer et al., 2015). The relatively high trophic level of humans (Heaton, 1986; Cabana and Rasmussen, 1996) combined with the treatment process, which usually favors the offgassing of $\left[{ }^{12} \mathrm{C}^{\mathrm{O}} \mathrm{O}_{2}\right.$ and $\left[{ }^{14} \mathrm{~N}\right] \mathrm{H}_{4}$ (Wayland and Hobson, 2001), generally results in MWWE having enriched carbon and nitrogen signatures relative to the waters into which they are released. The organisms that directly and indirectly consume sewage-derived nutrients often reflect this enriched signature in their body tissues (DeBruyn and Rasmussen, 2002; Loomer et al., 2015). Isotope fractionation can be complex though, particularly in primary producers where nutrient uptake is impacted by the available forms of nitrogen (primarily $\mathrm{NH}_{4}{ }^{+}, \mathrm{NO}_{3}$ and $\mathrm{NO}_{2}{ }^{-}$) as well as the local dissolved $\mathrm{CO}_{2}$ concentration (Finlay, 2004). Previous research in the Speed River in August 2008 found that the two most abundant fish species in the riffle habitats, Rainbow Darter (Etheostoma caeruleum) and 
Greenside Darter (E. blennioides), had similar $\delta^{13} \mathrm{C}$ and $\delta^{15} \mathrm{~N}$ signatures at reference sites upstream of the City of Guelph MWWE outfall (Brown et al., 2011). However, downstream of the outfall Rainbow Darter had elevated isotopic signatures compared to upstream, while Greenside Darter signatures did not change from those at reference sites. Brown et al. (2011) hypothesized that these two species may have utilized different food resources resulting from an increased amount of primary productivity downstream of the outfall. This coincided with a greater relative abundance of Rainbow Darter at the exposure site, which may have resulted in a competitive advantage gained as a result of nutrient input from the MWWE (Brown et al., 2011). Freshwater systems can be complex and the variability of fish abundances (Brown et al., 2011; Tetreault et al., 2013) and isotopic signatures in darters (Loomer, 2008; Loomer et al., 2015) have been shown to change seasonally in response to wastewater effluent outfalls. The objectives of this study were to 1) determine if the stable isotope signatures and relative abundances of Rainbow and Greenside Darter are consistent across seasons and years, 2) determine the $\delta^{13} \mathrm{C}$ and $\delta^{15} \mathrm{~N}$ pattern of benthic invertebrates upstream and downstream of the municipal wastewater effluent outfall, and 3) evaluate the stomach contents of darters to assess potential changes in diets (prey items) of the two darter species that may influence isotopic signatures and their relative abundances.

\section{Methods and Materials}

\subsection{Study Area and Site Characterization}

The Speed River is a tributary $\left(6^{\text {th }}\right.$ order stream $)$ of the Grand River in southern Ontario, which drains into Lake Erie. The Guelph Wastewater Treatment Plant is on the southwest side of Guelph, Ontario and its effluent is discharged from the west bank of the river downstream of the city (Figure 1). The current treatment of wastewater involves 
activated sludge secondary treatment and tertiary treatment that includes rotating biological contactors and slow sand filtration resulting in low levels (2009) of ammonia $(0.9 \mathrm{mg} / \mathrm{L}$ average) and suspended solids $(0-7 \mathrm{mg} / \mathrm{L})$. Nitrate is the dominant form of nitrogen released (22.3 $\mathrm{mg} / \mathrm{L}$ average), and some soluble phosphorus is removed during early treatment, lessening the downstream nutrient exposure (City of Guelph, pers. comm.; City of Guelph, 2011). Based on effluent and river flows the river can be $>20 \%$ effluent during the summer low flow periods. In addition it may take considerable distance for the effluent to fully mix. To characterize the effluent plume, conductivity and temperature measurements were taken on transects across the river between sites U3 and D4 on November 4, 2009. Temperature probes were also placed in the river during the open water season at several sites.

Fish and benthic invertebrates were sampled in July and August 2009 at 10 riffle/run sites along an $8.7 \mathrm{~km}$ stretch of river including waters upstream and downstream of the effluent outfall. Fish were also sampled at some of the same sites in May 2009, October 2009 and March 2010; this data set is available in the supplementary data. There were four reference sites upstream of the effluent outfall $(\mathrm{U} 1=1.2 \mathrm{~km}$ upstream, $\mathrm{U} 2=0.5 \mathrm{~km}, \mathrm{U} 3 \mathrm{~W}=$ $0.1 \mathrm{~km}, \mathrm{U} 3 \mathrm{E}=0.1 \mathrm{~km})$, and six sites downstream $(\mathrm{D} 1 \mathrm{~W}=0.1 \mathrm{~km}$ downstream, $\mathrm{D} 1 \mathrm{E}=0.1$ $\mathrm{km}, \mathrm{D} 2 \mathrm{~W}=1.0 \mathrm{~km}, \mathrm{D} 2 \mathrm{E}=1.1 \mathrm{~km}, \mathrm{D} 3=2.4 \mathrm{~km}, \mathrm{D} 4=7.5 \mathrm{~km}$ ). Three of the downstream sites were on the east bank (E), and were therefore only partially exposed to the sewage effluent. All sites were used in 2008 by Brown et al. (2011), except for D1E, D2W and D2E, which were added for this study. Sites were selected for their locations relative to the outfall, as well as for their similar stream morphologies (Brown et al., 2011). Site U1 was not used in analyses of darter abundances and benthic invertebrate communities due to the substrate, which was more embedded than the rest of the sites. 


\subsection{Fish and Benthic Invertebrate Collections}

To estimate Rainbow and Greenside Darter abundances, each site was divided into ten sub-sites $(10 \mathrm{~m} \times 10 \mathrm{~m})$, of which six were randomly selected to be sampled. These subsites were re-selected every sampling period and used to represent the entire site, providing sufficient power to evaluate differences among sites. Each selected sub-site was sampled in a zig-zag pattern covering its entire area using a backpack electroshocker (Smith-Root Model 12, LR-24, Smith-Root Inc., Vancouver, WA). Sampling effort was standardized to 300 sec/sub-site to allow for comparisons of fish abundance using catch per unit effort (CPUE). Electroshocker settings (voltage and pulse) were adjusted accordingly to account for variable conductivities between sites. One netter on each side of the electroshocker would simultaneously collect as many fish as possible. Collections were typically performed between 7:00 and 11:00 am, usually beginning just after daybreak to control for diurnal fish movements and to reduce sampling stress during warm air and water temperatures later in the day (Brown et al., 2011; Tetreault et al., 2013). Depending on capture success, 6 to 15 specimens of each darter species were collected from each site during July and August abundance sampling. Fresh samples were frozen at $-20^{\circ} \mathrm{C}$, and used later for stable isotope analysis and stomach content analysis. Selected Rainbow Darter ranged from 39-61 mm $( \pm 1$ $\mathrm{mm})$ in total length, and Greenside Darter ranged from 48-82 $\mathrm{mm}( \pm 1 \mathrm{~mm})$ in total length. All fish were handled according to protocols approved by the University of Waterloo Animal Care Committee (AUP \# 04-24 and 08-08).

Qualitative benthic invertebrate community samples were collected in August at sites U2, U3W, U3E, D1W, D1E, D2W, D2E and D3 using a modified version of the Canadian Aquatic Biomonitoring Network (CABIN) protocol (Environment Canada, 2012). In the 
middle of each site, a $500 \mu \mathrm{m}$ mesh D-net was used to collect one five minute traveling kick and sweep sample which spanned the entire $10 \mathrm{~m}$ width of the site (Environment Canada, 2012). Entire samples were immediately preserved in $70 \%$ ethanol. Sub-sampling was performed in the laboratory by randomly selecting a minimum of 300 invertebrates to represent each sample (Sebastien et al., 1988). Invertebrates were counted and identified to order or family level using Mackie (2005) and Merritt and Cummins (1996). A separate Dnet collection was used to collect benthic invertebrates for stable isotope analysis. Taxa that were abundant and common among sites (U1, U2, U3W, D1W, D2W, D3 and D4) were sorted to the lowest possible taxon (order, family or sub-family) and stored at $-20^{\circ} \mathrm{C}$ until analysis.

\subsection{Stomach Contents}

Stomachs were removed from darter specimens collected during abundance sampling. The contents from 6 to 15 stomachs of each species were analyzed from sites U2, U3W, D1W, D2E, D2W and D3 in July, and from U3W and D1W in May, August, October and March 2010, similar to Alford and Beckett (2007). Well preserved contents were identified to family level, and partially degraded contents were identified to the lowest possible taxonomic level using Mackie (2005) and Merritt and Cummins (1996). A tally of individual specimens, organized by family/taxon, was kept for each stomach, and results from fish of the same species were pooled together at each site for analysis.

\subsection{Stable Isotopes}

Both fish and invertebrate samples were prepared for instrumental analysis using methods similar to those previously described in Loomer et al. (2015) and Brown et al. 
(2011). Briefly, fish were thawed and a small fillet of skinless white dorsal epaxial muscle, anterior to the dorsal fin was immediately removed from each fish for analysis (Pinnegar and Polunin, 1999). The whole bodies of benthic invertebrates were cleaned with distilled water to remove any debris. All samples were then desiccated at $60^{\circ} \mathrm{C}$ for $24 \mathrm{~h}$, and ground into a fine homogenous powder using a mortar and pestle. A Delta Plus Continuous 26 Flow Stable Isotope Ratio Mass Spectrometer (Thermo Finnigan/Bremen-Germany) coupled to a Carlo Erba Elemental Analyzer (CHNS-O EA1108 - Italy) was used to measure $\delta^{15} \mathrm{~N}$ (indicates trophic level), $\delta^{13} \mathrm{C}$ (indicates carbon source), \% elemental nitrogen, and \% elemental carbon of the powdered samples (Drimmie and Hemmskerk, 2005). Every $12^{\text {th }}$ sample was run in duplicate and the variability in duplicate samples of fish and invertebrates was $0.08 \pm 0.01$

for $\delta^{13} \mathrm{C}$ and $0.29 \pm 0.03$ for $\delta^{15} \mathrm{~N}(\mathrm{n}=61)$. Correcting for the $\mathrm{C}: \mathrm{N}$ ratio of darter tissue did not make a difference in the interpretation of the data, therefore $\delta^{13} \mathrm{C}$ values of darters were not lipid-normalized (Robinson, 2011).

\subsection{Analysis}

Darter abundance data from July (measured in CPUE) did not fit a normal distribution, hence they were evaluated among sites using a Kruskal-Wallis test and a Dunn's pairwise comparison test $(\alpha=0.05)$. August abundance data were analyzed with a one-way ANOVA and Tukey pairwise comparison test $(\alpha=0.05) . \delta^{15} \mathrm{~N}$ and $\delta^{13} \mathrm{C}$ of fish were $\log$ transformed to fit a normal distribution and evaluated between species and among sites within each sampling period using a two-way ANOVA and Holm-Sidak multiple comparison test $(\alpha=0.05)$. With the exception of Decapoda, $\delta^{15} \mathrm{~N}$ and $\delta^{13} \mathrm{C}$ of the benthic invertebrates Gammaridae, Hydracarina and Isopoda $(n=3 /$ site) were analyzed among sites within each sampling period using a one-way ANOVA and Tukey pairwise comparison test $(\alpha=0.05)$. 
Decapoda ( $\mathrm{n}=6 /$ site) data did not follow a normal distribution and was evaluated using a Kruskal-Wallis test and Dunn's pairwise comparison test $(\alpha=0.05)$. Parametric and nonparametric analyses were performed in SigmaPlot Version 12.3.

A Bray-Curtis index of dissimilarity cluster analysis was used to compare benthic invertebrate communities among sites in August using the statistical software PAST version 2.17c (Hammer et al., 2001). The Bray-Curtis index of dissimilarity was also used to compare each exposed downstream site with the average upstream reference community (U2, U3W and U3E). The Bray-Curtis index of dissimilarity (B), is presented as similarity (1-B), where a value of 1 means that the sites have the same composition. Statistics were calculated using benthic invertebrate count data that had been converted to proportions. The Schoener index (Schoener, 1970) was used to compare the percent overlap of the diets of darters within sites and among sites between darter species. In the Schoener index, values range between 0 and 1 , where 0 indicates no overlap, and 1 indicates complete diet overlap. The index was calculated using the proportions of taxa found in fish stomach contents.

\section{RESULTS}

\subsection{Site Characterization}

The homogeneity of conductivity and water temperatures measured along a crosssection of the Speed River demonstrated that effluent released from the outfall stayed close to the exposed west shore, until the river completely mixed about five kilometers downstream (Figure 2). The effluent mixed gradually with river water, and created a profile with a smooth gradient of decreasing effluent concentrations approaching the east shore (Figure 2). In the current study, sites immediately downstream of the outfall (D1W and D1E) were not fully 
mixed during the various sampling periods based on water temperature, conductivity and appearance of aquatic moss and filamentous algae (Figure S1, Table S3).

\subsection{Darter Abundances}

In July, Rainbow Darter were significantly more abundant at the immediate downstream site (D1W) than upstream (U3E) and further downstream (D3) (Figure 3a). Rainbow Darter were significantly more abundant (higher CPUE) at D1W than at all other sites in August except for U3W and D2E (Figure 3b). In both months there were a low number of Greenside Darter at D1W (Figure 3a and b). The CPUE at this site (D1W) in August was $71.8 \pm 11.8$ and $4.7 \pm 1.3$ fish/300s for Rainbow and Greenside Darter, respectively. There was a $202 \%$ increase in the number of Rainbow Darter collected at D1W from July (35.5 $\pm 5.7 \mathrm{fish} / 300 \mathrm{~s})$ to August. Compared to the average upstream abundance (U2, U3W and U3E), there were 316\% more Rainbow Darter and 294\% less Greenside Darter at D1W in the August sampling period. Along the unexposed east bank (site D1E) there were significantly fewer Rainbow Darter $(\mathrm{p}=0.032)$, but a similar number of Greenside Darter $(\mathrm{p}=0.803$ ) relative to D1W (Figure $3 b)$. The number of Rainbow Darter captured at D1W in October decreased substantially to $17.4 \pm 4.5$ fish $/ 300$ s, while the number of Greenside Darter also reduced to $1.5 \pm 0.6$ fish/300s (Table S1). This trend also occurred at most other sites in October, possibly reflecting the seasonal migration of darters to different habitats.

\subsection{Benthic Invertebrate Community}

Benthic invertebrate collections across all sites consisted of 23 total Ephemeroptera, Plecoptera, Trichoptera and Diptera families, and 11 other taxonomic orders. Ephemeroptera, Coleoptera and Isopoda were the most abundant of all taxonomic groupings. Benthic 
invertebrate communities downstream of the MWWE outfall were of different species composition than upstream reference sites in August of 2009. Bray-Curtis indices of dissimilarity between D1W and the upstream reference average was 0.340 , and the next two most exposed sites downstream (D2W and D3) became gradually more similar to the upstream reference average with similarity values of 0.461 and 0.613 , respectively. A cluster analysis using the Bray-Curtis index (co-phenetic correlation coefficient $=0.8121)$ comparing sites, revealed the three most exposed sites (D1W, D2W and D3) cluster together (60\% similarity) (Figure 4). Presence of the isopod Caecidotea intermedius at exposed sites contributed heavily towards these differences. C. intermedius represented $64.0 \%$ of invertebrates at D1W, 47.7\% at D2W, and 25.8\% at D3 in August. Whereas, the reference site average contained only $8.9 \%$ isopods. Elmidae was the secondary taxon driving community differences, where the number of elmids was reduced at the two most exposed sites (D1W and D2W), which contained 2.6\% and 6.6\% elmids, respectively. The reference site average abundance of Elmidae was $28.2 \%$ (Figure S3). The benthic invertebrate communities at reference sites (U2, U3W, U3E) and the site adjacent to but not directly exposed to the effluent discharge (D2E) clustered together with more than $60 \%$ similarity in August (Figure 4). Cluster analysis in July and October also indicated different species compositions downstream of the outfall. Upstream reference sites (U2 and U3W) clustered together with 55\% and 43\% similarity in July and October, respectively (Figure S1).

\subsection{Stable Isotope Analysis}

Stable carbon isotopes $\left(\delta^{13} \mathrm{C}\right)$ of benthic invertebrate groups in August demonstrated a range of -34.18 to $-25.63 \%$, confirming the presence of multiple feeding guilds (including grazers, collectors and predators). Invertebrates showed enriching trends immediately 
downstream of the MWWE outfall (Figure 5), indicating that sewage-derived nutrients may be becoming incorporated into the tissues of these organisms. Of those invertebrate groups tested, statistically significant enrichment was measured only in Gammaridae $(\mathrm{p}=0.001)$. Carbon signatures of darters were in the middle of the range of invertebrate carbon signatures, with Rainbow Darter closely following the downstream enrichment pattern observed in invertebrates. Carbon signatures in Greenside Darter failed to show this enrichment at D1W in August (Figure 6b), however earlier in July, signatures were enriched at D1W compared to U3W, and followed a similar pattern to Rainbow Darter at that time (Figure 6a).

In August, stable isotope signatures of nitrogen $\left(\delta^{15} \mathrm{~N}\right)$ in benthic invertebrate groups demonstrated a range of 7.87 to $13.79 \%{ }^{15} \mathrm{~N}$ (Figure 5). There was a significant enrichment from U3W to D1W in Orconectes rusticus ( $\mathrm{p}<0.05)$, Isopoda $(C$. intermedius $)(\mathrm{p}=0.009)$ and Gammaridae $(\mathrm{p}<0.001)$. This overall trend of $\delta^{15} \mathrm{~N}$ enrichment from upstream to downstream was observed in most other invertebrate groups, however in those groups tested, the results were not always statistically significant. Darter signatures were roughly one trophic level higher ( 4 \%) than the invertebrates collectively (Minagawa and Wada, 1984). In August, Rainbow Darter signatures peaked at $-28.3 \%{ }^{13} \mathrm{C}$ and $17.3 \%{ }^{15} \mathrm{~N}$ at D1W, while $\delta^{15} \mathrm{~N}$ in Greenside Darter increased only slightly but not significantly immediately downstream of the discharge. Signatures peaked $1.1 \mathrm{~km}$ further downstream (D2W) at $-28.6 \% \delta^{13} \mathrm{C}$ and $16.0 \%$ o $\delta^{15} \mathrm{~N}$. Greenside Darter $\delta^{13} \mathrm{C}$ and $\delta^{15} \mathrm{~N}$ from the east banks of the two immediate downstream sites (D1E and D2E) had very similar signatures to Greenside Darter on the west banks (D1W and D2W). The $\delta^{13} \mathrm{C}$ of Greenside Darter at D2E (partial effluent exposure) were slightly less enriched than those at D2W ( $\mathrm{p}=0.043)$. The $\delta^{13} \mathrm{C}$ and $\delta^{15} \mathrm{~N}$ of Rainbow Darter 
from the east bank (D1E and D2E) were less enriched than those from along the exposed west bank and upstream reference sites (Figure 6b). At D2E, signatures showed slight enrichment compared to immediately upstream (U3W) and D1E, but there were no statistical differences. The average difference between duplicate samples of fish and invertebrates was $0.08 \pm 0.01$ for $\delta^{13} \mathrm{C}$ and $0.29 \pm 0.03$ for $\delta^{15} \mathrm{~N}(\mathrm{n}=61)$

\subsection{Stomach Content Analysis}

Stomach contents of darters varied throughout the year, but were typically comprised mostly of Chironomidae, particularly of the Orthocladiinae sub-family. Trichoptera, Ephemeroptera and Isopoda were also common in some species during part of the year, however some stomachs were also empty $(6.0 \%$ and $7.7 \%$ in July and $24 \%$ and $4.0 \%$ in August for Rainbow Darter and Greenside Darter, respectively). Rainbow Darter and Greenside Darter diets were similar in May, with a 93\% Schoener overlap at U3W and 86\% at D1W (Table 1). The types of invertebrate taxa found in the stomachs of both species diversified in July (Table S2a), and diet overlap between species decreased within all sites (Schoener values between 38\% and 63\%). Darter diets remained diverse in August, and diet overlap between species was low. The lowest diet overlap value between species was observed in October with a 36\% overlap at site D1W. Schoener overlap values between upstream and downstream Rainbow Darter (U3W vs. D1W) were similar in all months, except for October, where a 32\% diet overlap resulted from an abundance of chironomid larvae (Chironomidae) in upstream stomachs, and a lack of isopods (Figure 7, Table S2b). Isopods (C. intermedius) were a notable inclusion to Rainbow Darter diets both upstream and downstream of the MWWE outfall in August and October, and were rarely observed in Greenside Darter stomachs (Figure 7, Table S2b). In October, Greenside Darter diets, and 
upstream Rainbow Darter diets all contained mostly chironomids, similar to stomach contents of both species in spring (May 2009) and late winter (March 2010) (Table 1, Table S2a, b). Mites (Hydracarina) contributed notably to the diets of Rainbow Darter throughout the seasons, and were only found sparingly in Greenside Darter stomachs (Table S2). In August, caddisfly larvae (Trichoptera) were prominent in Greenside Darter downstream of the MWWE outfall.

\section{Discussion}

This study demonstrates that exposure to a MWWE plume can alter the downstream benthic invertebrate community, and may influence the abundances of Rainbow and Greenside Darter and the food that they consume in the receiving environment. Immediately downstream of the outfall, stable carbon and nitrogen isotopic signatures revealed that the feeding behaviors of Rainbow and Greenside Darter diverged from each other between July and August, coinciding with a change in the benthic invertebrate community. Rainbow Darter were much more abundant at this site than Greenside Darter during this time period, supporting the hypothesis that this species was able to utilize the available resources

(including an increased abundance of Isopoda) more efficiently than Greenside Darters at this same location.

These findings are similar to those of previous studies which have shown fish and benthic invertebrates (Kosmala et al., 1999; Grantham et al., 2012) to be impacted by sewage-derived nutrient inputs from MWWEs. In fish communities, nutrient inputs were shown to reduce the diversity of downstream feeding guilds to mostly generalist invertebratefeeding species (Reash and Berra, 1987). Schlosser (1982) noted the presence of heavy 
organic substrate from autotrophic growth in the summer months as one likely factor that could drive fish species composition to contain more generalists. Since Rainbow Darter seem to be a generalist species, it is hypothesized that heavy algae and macrophyte growth observed immediately downstream of the MWWE in the Speed River in 2008 (Brown et al., 2011) and 2009 (Table S3), may have facilitated their dominance at D1W in August. Porter and Janz (2003) found a tolerant cyprinid species to dominate similarly in a stream impacted by MWWE, however, it should be noted that effluent exposure does not always produce increased fish abundance (Yeom et al., 2007). Having observed very similar trends in the stable isotope signatures and relative abundances of darters in consecutive years (Brown et al., 2011), it can be surmised that there is an annual impact occurring downstream of the MWWE outfall. It seems clear that conditions in the effluent plume change during the year, becoming more favorable for Rainbow Darter than Greenside Darter in the summer.

Impacts to the benthic community were highlighted by an increased proportion of Isopoda (Caecidotea intermedius) within the effluent plume. Isopods are typically collectorgatherers and are considered to be tolerant of adverse environmental conditions (Simon and Buikema Jr, 1997). The dramatic change in invertebrate communities at the exposed sites presumably provided darters living in these conditions with a much different selection of available food than at unexposed sites. Stomach contents of these fish revealed isopods $(C$. intermedius) in the diets of Rainbow Darter at the immediate downstream site (D1W) in August and October. The incorporation of isopods into their diets is suspected to be the main factor driving Schoener diet overlap values to differ from Greenside Darter in August and October. Both darter diets diversified in the summer, demonstrating a generalist and opportunistic behavior common to many stream fishes (Wynes and Wissing, 1982; Hansen et 
al., 1986; Hlohowskyj and White, 1983), however isopods were absent from nearly all Greenside Darter stomachs. Wynes and Wissing (1982) found Rainbow Darter to consume a wider range of food sizes and taxa in the presence of Greenside Darter. These results would seem to suggest a similar ability to adapt to a wide range of food taxa in the Speed River. Rainbow Darter have a terminal mouth and so may pick food off of the tops and sides of rocks or plants (Page and Swofford, 1984; Schlosser and Toth, 1984), while Greenside Darter have a subterminal mouth and feed primarily off of the tops of rocks (Page and Swofford, 1984). Based on these differences in feeding techniques, the different $\delta^{15} \mathrm{~N}$ of Greenside Darter at site D1W in August could be explained a couple of ways. They may have shifted their diets in the summer to a less enriched food source in the MWWE plume, or they may have consumed invertebrates that were not exposed to the effluent at all.

Greenside Darter contained ephemeropterans in their August diets, and considering Baetidae also had the lowest $\delta^{15} \mathrm{~N}$ of all invertebrates it could be an indication that they were consuming less enriched food within the plume. However, Rainbow Darter at D1W also consumed ephemeropterans during August, so a more detailed stomach content and stable isotope analysis study would be required to confirm these results. The latter explanation would mean that Greenside Darter were feeding perpendicular to the effluent plume (at or near site D1E), or upstream where invertebrate signatures were naturally less enriched. If this holds to be true, it may indicate that these fish are more mobile than previously thought and as a result could have implications for these fish being utilized as sentinel species for biological monitoring. This explanation is supported by the stable isotope signatures $\left(\delta^{13} \mathrm{C}\right.$ and $\delta^{15} \mathrm{~N}$ ) of Greenside Darter from along the shore opposite of the effluent plume (D1E), which were similar to those at site D1W in July and August. It is unlikely that darters would 
travel distances of more than $100 \mathrm{~m}$ to feed upstream of the MWWE (Tetreault et al., 2011). It is possible that fish captured at D1W had been feeding outside of the plume on the east bank and/or were caught on the edge of the D1W sample area in the faster flowing water near the middle of the river which was potentially less influenced by the effluent. Greenside Darter are one of the largest in the Etheostoma genera, utilizing habitat that typically consists of unembedded cobble and boulder substrate (Bunt et al., 1998; Hlohowskyj and Wissing, 1986; Chipps et al., 1994) in deep, fast water (Stauffer et al., 1996; Chipps et al., 1994); more typical of the thalweg of a small river, such as the Speed. Rainbow Darter are often found in slower and shallower areas closer to shore than Greenside Darter (Harding et al., 1998), and have more generic preferences for substrate size (Hlohowskyj and Wissing, 1986; Wynes and Wissing, 1982; Schlosser and Toth, 1984). Both species will frequently cohabitate the same riffle or run, but they have evolved to adapt to specific types of microhabitat rather than competing directly with one another for resources (Stauffer et al., 1996; Page and Swofford, 1984; van Snik Gray and Stauffer, 1999). Considering this, it is possible that rather than outcompeting Greenside Darter, Rainbow Darter had a greater ability to become a generalist feeder at site D1W, and were more effective at utilizing the microhabitat and food available in the summer. To adapt to the summer microhabitat (heavy plant and algae growth) at D1W, it seems plausible that Greenside Darter may have had to forage outside of the effluent plume in order to successfully feed.

Although the Guelph effluent receives tertiary treatment, it is possible that other factors associated with the effluent may have impacted (e.g., toxicity) or altered the behavior (e.g., avoidance) of one species of darter more than the other causing some of the observed changes downstream. The effluent has previously been shown to alter endocrine function as 
well as stress responses in Rainbow Trout held in cages or exposed in the laboratory (Ings et al., 2011; 2012). Rainbow and Greenside Darter have also been shown to exhibit endocrine disruption, including intersex (testes-ova) in the Grand River, although the responses in the Speed River associated with the Guelph outfall were minimal (Tanna et al., 2013; Tetreault et al., 2014).

To further understand the observed responses in darters exposed to MWWE, future studies should focus on understanding the relationships among the physical and biological habitat and darter life history and morphometric characteristics. As demonstrated in this study and Brown et al. (2011), exposure to effluent (including high nutrient levels and an unnatural temperature regime; Table S3) produced a much different environment with greater macrophyte and algae cover (Table S4). Non-impacted temperate streams undergo natural seasonal shifts in temperature and primary productivity, impacting fish abundance and life history strategies (Schlosser, 1982). In the current study, the responses of darters to effluent varied across the seasons. Understanding how seasonal variation is impacted by exposure to MWWE may have important implications for understanding ecosystem responses and design of monitoring programs. Daily and seasonal mobility of darter species is also important for better understanding exposure and potential effects. A better understanding of these factors may allow more accurate predictions regarding changes in abundances, and support improved biological monitoring. Use of stable isotopes may be a potentially powerful tool for detecting subtle but potentially significant changes in ecosystems that could be linked to fish performance and their interactions with impacted receiving environments.

\section{Conclusion}


In conclusion, Rainbow Darter, but not Greenside Darter, reflected the enriched $\delta^{13} \mathrm{C}$ and $\delta^{15} \mathrm{~N}$ of most invertebrates immediately downstream of the MWWE outfall in late summer of 2009. These results support and provide explanation to those results reported by Brown et al. (2011) for fish collected in August 2008. Most invertebrates and fish (Rainbow Darter) followed similar seasonal and spatial isotopic patterns occurring from exposure to wastewater effluent. In contrast, the lack of a shift in isotopic signatures in late summer in Greenside Darter appears to be linked to a shift in their diet, whereby they began to obtain food with lower isotopic signatures within the effluent plume, or from foraging outside of it. These results suggest that there are subtle yet detectable changes in the behavior of fish in response to effluent discharges of a tertiary treated wastewater plant. This study supports the need for further knowledge of impacts of MWWE exposure on the physical and biological habitat of the receiving environment. Further investigation into the mobility and seasonal movements of darters will be important as these fish may be more mobile than previously thought. This has implications on these fish being utilized as sentinel species for biological monitoring and assessing the impact of future facility upgrades and trace organic pollutants in the environment (Tetreault et al., 2014). Despite the high quality of the effluent, subtle ecological impacts could become more pronounced in the future as the population and effluent quantity and quality change.

\section{Acknowledgements}

The authors would like to acknowledge the significant contributions of the field crew, most notably R. Tanna, S. Lyons and P. Njuru. Funding for this study was provided by the City of Guelph, NSERC Collaborative Research and Development Grant, Canadian Water Network 
and Canada Research Chairs Program to MRS. Technical support was provided through Environment Canada (MEM) at the National Water Research Institute. 


\section{References}

Alford JB, Beckett DC. 2007. Selective predation by four darter (Percidae) species on larval chironomids (Diptera) from a Mississippi stream. Environ Biol Fish 78(4): 353-364.

Brown CJM, Knight BW, McMaster ME, Munkittrick KR, Oakes KD, Tetreault GR, Servos MR. 2011. The effects of tertiary treated municipal wastewater on fish communities of a small river tributary in southern Ontario, Canada. Environ Pollut 159(7): 1923-1931.

Bunt CM, Cooke SJ, McKinley RS. 1998. Creation and maintenance of habitat downstream from a weir for the Greenside Darter, Etheostoma blennioides-a rare fish in Canada. Environ Biol Fish 51(3): 297-308.

Cabana G, Rasmussen JB. 1996. Comparison of aquatic food chains using nitrogen isotopes. P Natl Acad Sci USA 93(20): 10844.

Chambers P, Allard M, Walker S, Marsalek J, Lawrence J, Servos M, Busnarda J, Munger K, Adare KEA. 1997. Impacts of municipal wastewater effluents on Canadian waters: A review. Water Qual Res J Can 32(4): 659-713.

Chipps SR, Perry WB, Perry SA. 1994. Patterns of microhabitat use among four species of darters in three Appalachian streams. Am Midl Nat 131(1): 175-180.

City of Guelph. 2011. Wastewater Treatment Plant 2010 Annual Report. City of Guelph, Guelph, ON, Canada.

City of Guelph. Personal communication with Russell Atkins on March 10, 2011. Final effluent quality data from the Guelph wastewater treatment plant 2009.

DeBruyn AMH, Rasmussen JB. 2002. Quantifying assimilation of sewage-derived organic matter by riverine benthos. Ecol Appl 12(2): 511-520.

Drimmie RJ, Hemmskerk AR. 2005. Leco combustion of organics. In Technical Procedure 9.0, Revision 02. Environmental Isotope Laboratory, Department of Earth Sciences, University of Waterloo, Waterloo, ON.

Environment Canada. 2001. The state of municipal wastewater effluents in Canada. Ottawa (ON): Minister of Public Works and Government Services Canada ISBN 0-662-29972-8 [online]. http://publications.gc.ca/collections/Collection/EN1-11-96E.pdf (Accessed 20.03.15).

Environment Canada, 2012. Canadian Aquatic Biomonitoring Network (CABIN) Field Manual. ISBN978-1-100-20816-9 [online]. http://publications.gc.ca/collections/collection_2012/ec/En84-87-2012-eng.pdf (Accessed 20.02.15). 
Finlay JC. 2004. Patterns and controls of lotic algal stable carbon isotope ratios. Limnol Oceanogr 49(3): 850-861.

Gowda TP. 1983. Modelling nitrification effects on the dissolved oxygen regime of the Speed River. Water Res 17(12): 1917-1927.

Grand River Conservation Authority. 2005. Grappling with growth. In The Grand: Watershed Report. Grand River Conservation Authority, Cambridge, ON. [online]. http://www.grandriver.ca/WatershedReportCard/2005_Fall_Grand.pdf (Accessed 20.2.2015).

Grand River Conservation Authority. 2012. Assessment of future water quality conditions in the Grand and Speed Rivers. Water Management Plan Assimilative Capacity Working Group. Grand River Conservation Authority, Cambridge, ON. [online]. http://www.grandriver.ca/waterplan/TechBrief_AssimilativeCapacity_2012.pdf (Accessed 20.2.2015).

Grantham TE, Cañedo-Argüelles M, Perrée I, Rieradevall M, Prat N. 2012. A mesocosm approach for detecting stream invertebrate community responses to treated wastewater effluent. Environ Pollut 160: 95-102.

Hammer O, Harper DAT, Ryan PD. 2001. PAST: Paleontological Statistics software package for education and data analysis. Palaeontologica Electronica 4(1):1-9.

Hansen MJ, Gloss SP, Peckarsky BL. 1986. Predator species richness and prey population variability: Effects on diets of benthic stream fishes. Am Midl Nat 115(1): 63-72.

Harding JM, Burky AJ, Way CM. 1998. Habitat preferences of the Rainbow Darter, Etheostoma caeruleum, with regard to microhabitat velocity shelters. Copeia 1998(4): 988997.

Hlohowskyj I, Wissing TE. 1986. Substrate selection by Fantail (Etheostoma flabellare), Greenside (E. blennioides), and Rainbow (E. caeruleum) Darters. Ohio J Sci 86(3): 124-129.

Hlohowskyj I, White AM. 1983. Food resource partitioning and selectivity by the Greenside, Rainbow, and Fantail Darters (pisces: Percidae). Ohio J Sci 83(4): 201-208.

Ings, J, Servos M, Vijayan M. 2011. Hepatic transcriptomics and protein responses to in situ municipal wastewater effluent exposure in rainbow trout. Environ Sci Technol 45(6): 23682376

Ings, JS, Vijayan MM, Servos MR. 2012. Temporal changes in stress and tissue-specific metabolic responses to municipal wastewater effluent exposure in rainbow trout. Comp Biochem Physiol - C Toxicol Pharmacol 156 (2): 67-74. 
Kosmala A, Charvet S, Roger MC, Faessel B. 1999. Impact assessment of a wastewater treatment plant effluent using instream invertebrates and the Ceriodaphnia dubia chronictoxicity test. Water Res. 33(1): 266-278.

Loomer HA. 2008. The dynamics of carbon and nitrogen stable isotope signatures of aquatic food webs in the Grand River watershed. M.Sc., Department of Biology, University of Waterloo, Waterloo, ON, Canada.

Loomer, H, Oakes K, Schiff S, Taylor W, Servos M. 2015. Use of stable isotopes to trace municipal waste water effluents into food webs within a highly developed river system. River Res. Appl. http://dx.doi.org/10.1002/rra.2826 in press

Mackie GL. 2005. Aquatic flora and invertebrate fauna of the Speed River watershed. University of Guelph, Guelph, ON, Canada.

Merritt RW, Cummins KW. 1996. An introduction to the aquatic insects of North America. Kendall/Hunt Publishing Company, Dubuque, IA, USA.

Minagawa M, Wada E. 1984. Stepwise enrichment of ${ }^{15} \mathrm{~N}$ along food chains: Further evidence and the relation between $\delta^{15} \mathrm{~N}$ and animal age. Geochim Cosmochim Ac 48(5): 1135-1140.

Page LM, Swofford DL. 1984. Morphological correlates of ecological specialization in darters. Environ Biol Fish 11(2): 139-159.

Peterson BJ, Fry B. 1987. Stable isotopes in ecosystem studies. Annu Rev Ecol Syst 18(1): 293-320.

Pinnegar JK, Polunin NVC. 1999. Differential fractionation of $\delta^{13} \mathrm{C}$ and $\delta^{15} \mathrm{~N}$ among fish tissues: Implications for the study of trophic interactions. Funct Ecol 13(2): 225-231.

Porter CM, Janz DM. 2003. Treated municipal sewage discharge affects multiple levels of biological organization in fish. Ecotox Environ Safe 54(2): 199-206.

Reash RJ, Berra TM. 1987. Comparison of Fish Communities in a Clean-water System and an Adjacent Polluted Stream. Am Midl Nat 118(2): 301-322.

Robinson CR. 2011. The city and the stream: Impacts of municipal wastewater effluent on the riffle food web in the Speed River, Ontario. M.Sc., Department of Biology, University of Waterloo, Waterloo, ON, Canada.

Schlosser IT. 1982. Trophic structure, reproductive success, and growth rate of fishes in a natural and modified headwater stream. Can J Fish Aquat Sci 39: 968-978. 
Schlosser IJ, Toth LA. 1984. Niche relationships and population ecology of Rainbow (Etheostoma caeruleum) and Fantail (E. flabellare) Darters in a temporally variable environment. Oikos 42(2): 229-238.

Sebastien RJ, Rosenberg DM, Wiens AP. 1988. A method for subsampling unsorted benthic macroinvertebrates by weight. Hydrobiologia 157(1): 69-75.

Servos MR, Bennie DT, Burnison BK, Jurkovic A, McInnis R, Neheli T, Schnell A, Seto P, Smyth SA, Ternes TA. 2005. Distribution of estrogens, $17 \beta$-estradiol and estrone, in Canadian municipal wastewater treatment plants. Sci Total Environ 336: 155-170.

Simon KS, Buikema Jr AL. 1997. Effects of organic pollution on an Appalachian cave: changes in macroinvertebrate populations and food supplies. Am Midl Nat 138(2): 387-401.

Stauffer JR, Boltz JM, Kellogg KA, Snik ES. 1996. Microhabitat partitioning in a diverse assemblage of darters in the Allegheny River system. Environ Biol Fish 46(1): 37-44.

Tanna, R, Tetreault G, Bennett C, Bragg L, Oakes K, McMaster M, Servos M. 2013. Occurrence and degree of intersex (testis-ova) across an urban gradient in the Grand River, Ontario, Canada. Environ Toxicol Chem 32(9): 1981-91.

Tetreault GR, Bennett CJ, Shires K, Knight B, Servos MR, McMaster ME. 2011. Intersex and reproductive impairment of wild fish exposed to multiple municipal wastewater discharges. Aquat Toxicol 104(3): 278-290.

Tetreault GR, Brown CJM, Bennett CJ, Oakes KD, McMaster ME, Servos MR. 2013. Fish community responses to multiple municipal wastewater inputs in a watershed. Integrated Environ Assess Manag 9(3): 456-468.

Tetreault GR, Bennett CJ, Servos MR, McMaster ME. 2014. Optimization of effectsassessment of Greenside Darter (Etheostoma blennioides) exposed to tertiary treated municipal wastewater based on seasonal changes of reproductive endpoints. Environ Toxicol Chem 33(5): 1077-1089.

van Snik Gray E, Stauffer JR. 1999. Comparative microhabitat use of ecologically similar benthic fishes. Environ Biol Fish 56(4): 443-453.

Wayland M, Hobson KA. 2001. Stable carbon, nitrogen, and sulfur isotope ratios in riparian food webs on rivers receiving sewage and pulp-mill effluents. Can J Zoolog 79(1): 5-15.

Wynes DL, Wissing TE. 1982. Resource sharing among darters in an Ohio stream. Am Midl Nat 107(2): 294-304.

Yeom DH, Lee S, Kang GS, Seo J, Lee SK. 2007. Stressor identification and health assessment of fish exposed to wastewater effluents in Miho Stream, South Korea. Chemosphere 67(11): 2282-2292. 


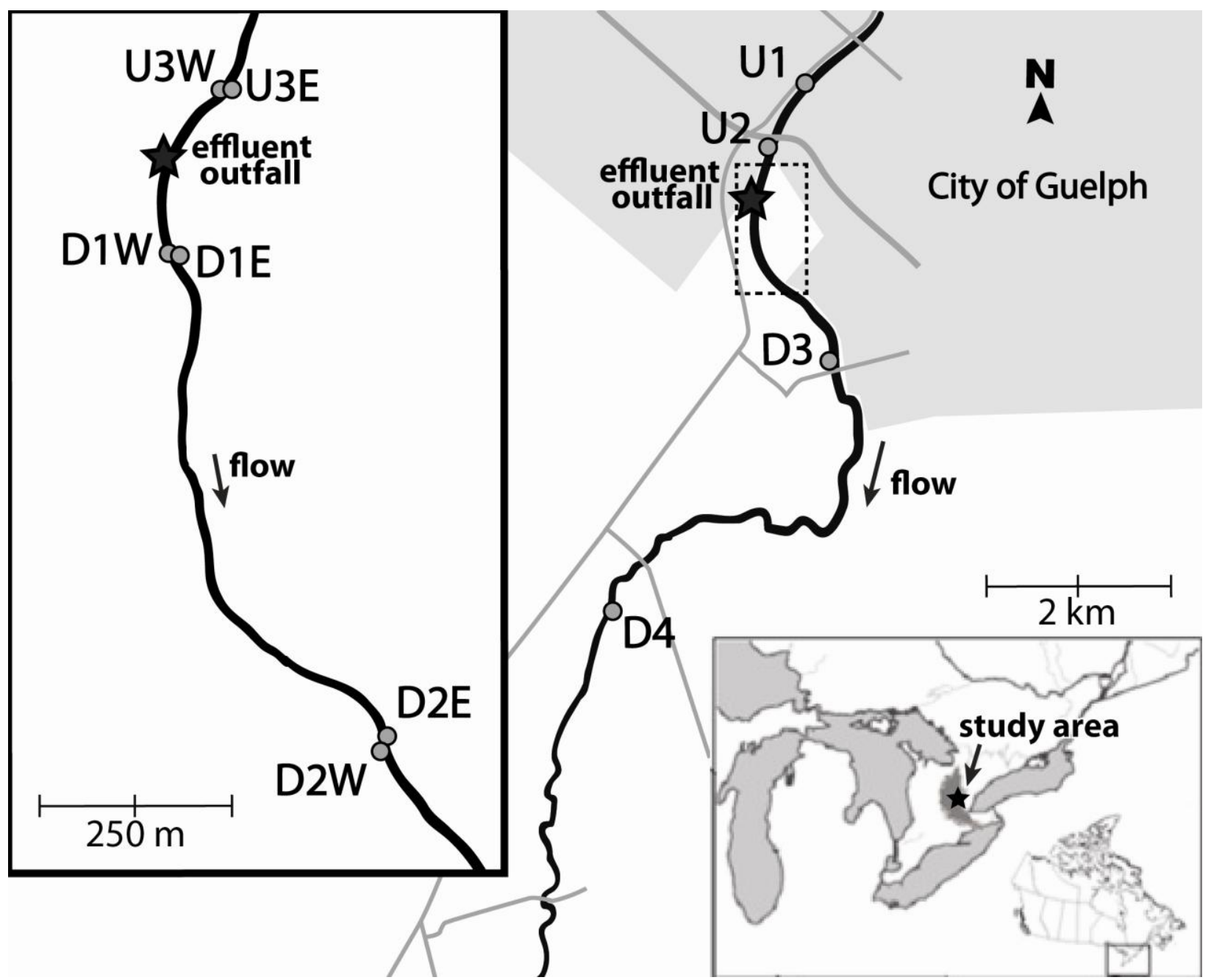

Figure 1. Map of the Speed River downstream of Guelph, Ontario, Canada including sampling sites used for fish and invertebrate collections.

1 COLUMN FIGURE 


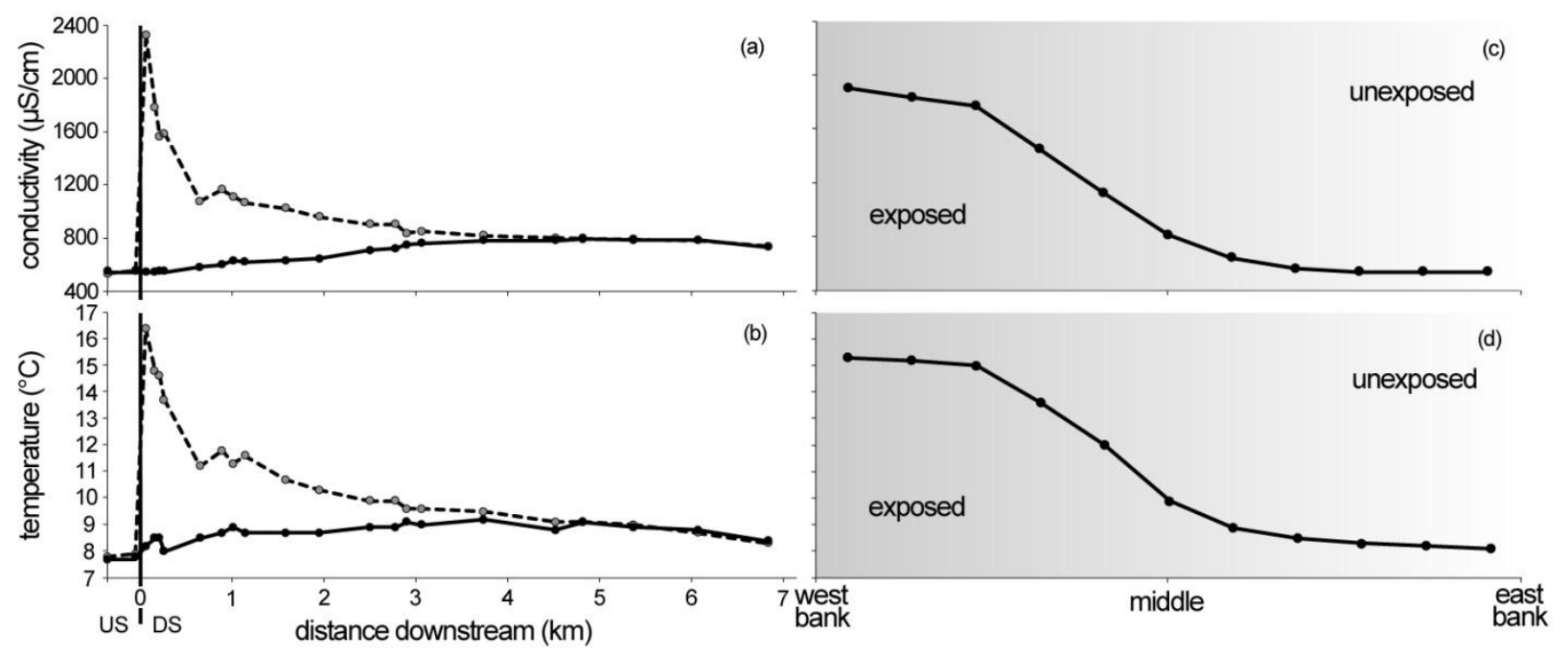

Figure 2. Surface water (a) conductivity and (b) temperature measured five meters from the west bank (dashed line) and the east bank (solid line) in the Speed River upstream and downstream of the Guelph MWWTP discharge on November 4, 2009. Measured (c) conductivity and (d) temperature of surface water on a perpendicular transect from the west bank to the east bank of the river immediately downstream of the effluent outfall in the middle of site D1W.

\subsection{COLUMN FIGURE}



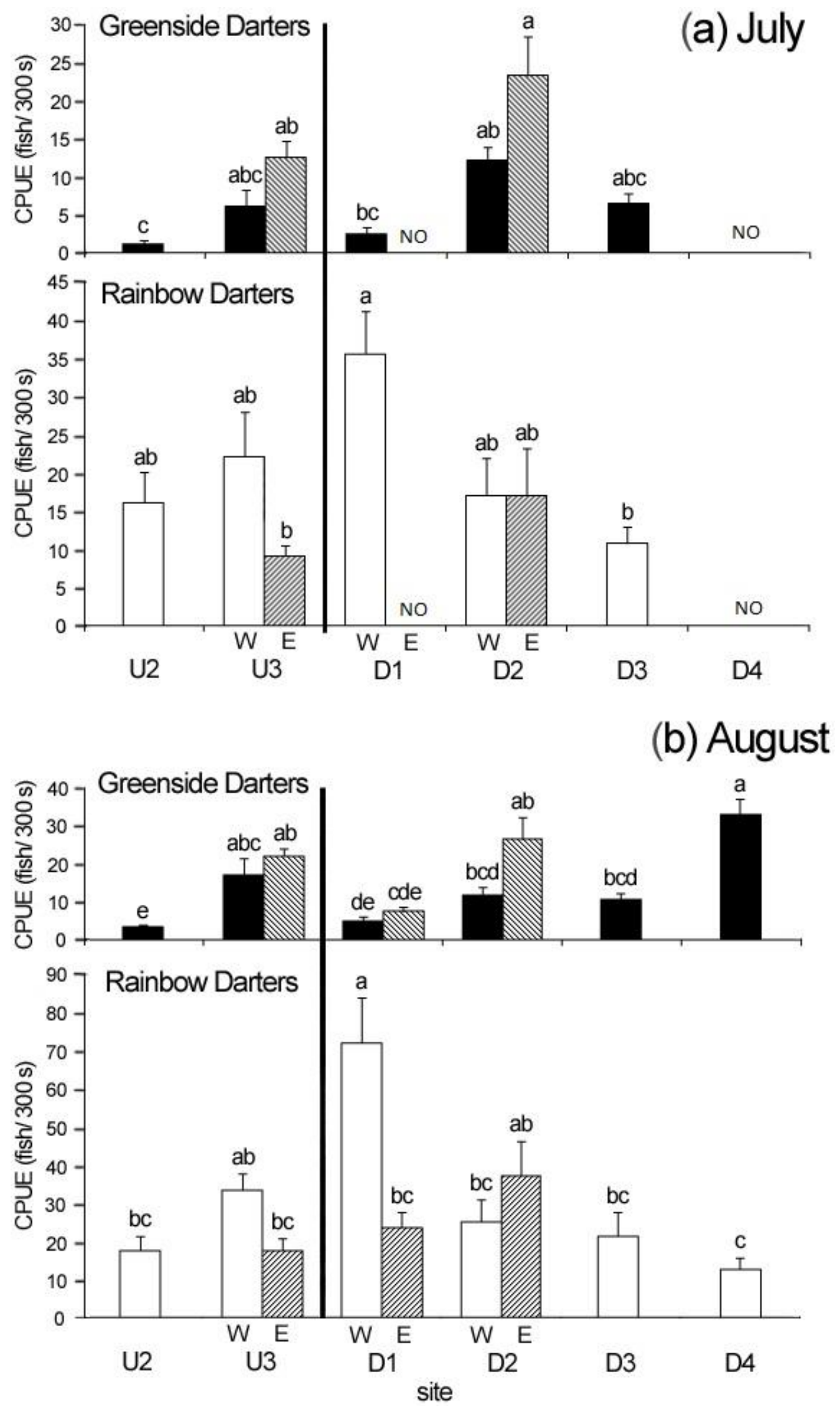
Figure 3. Mean abundances in catch per unit effort (CPUE $=$ \#fish/300s \pm SE) of Rainbow (light bars) and Greenside Darters (dark bars) at sites in the Speed River in August 2009. Solid bars indicate fish caught along the west bank and patterned bars indicate fish caught along the east bank. Letters denote significant differences among sites as determined by Kruskal-Wallis and Dunn's post-hoc tests in July, and ANOVA and Tukey post-hoc tests in August (n=6). No fish observed is indicated by "NO"; Fish were collections were not attempted at D1E or D4 in July.

\section{COLUMN FIGURE}



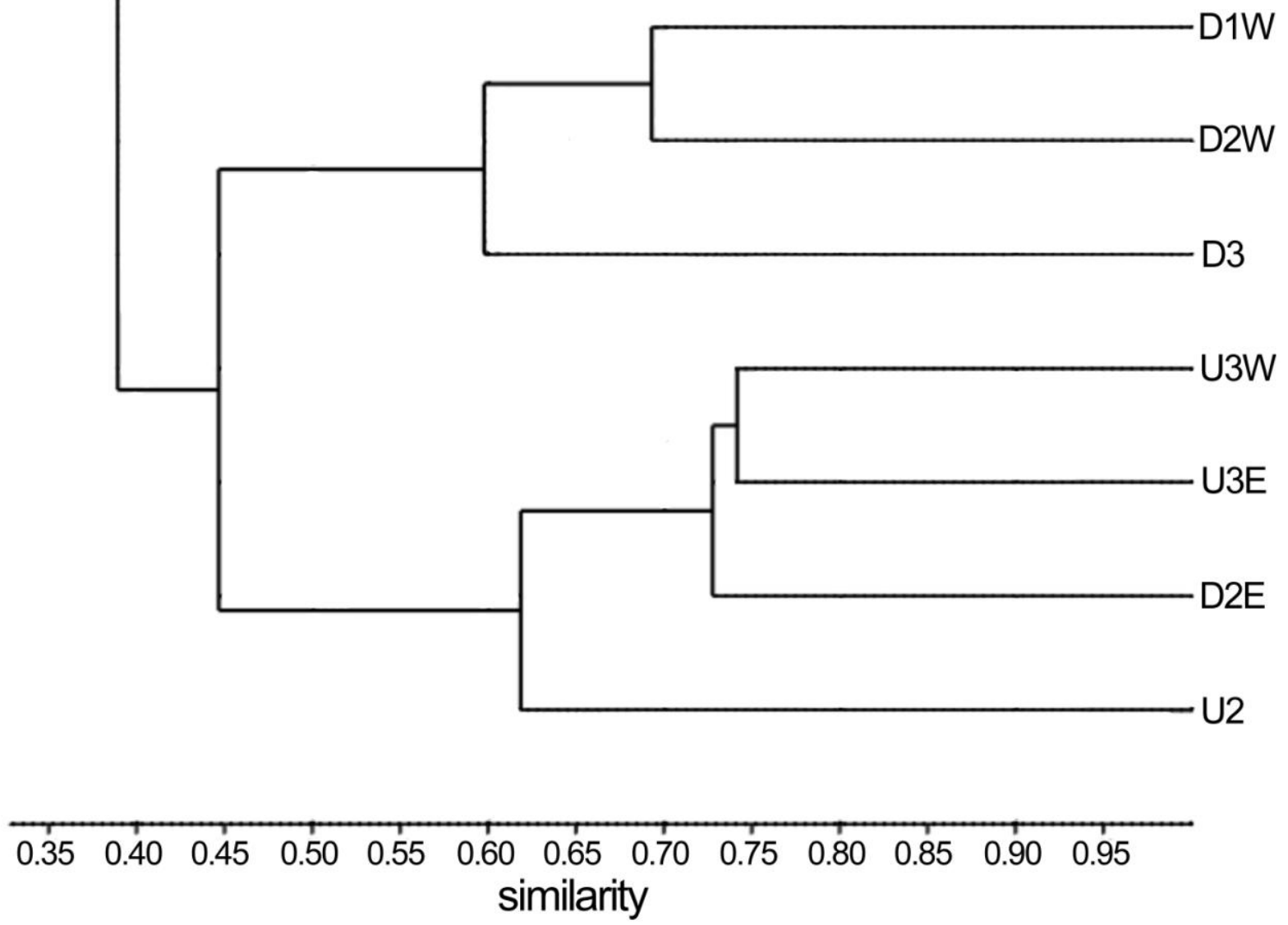

Figure 4. Bray-Curtis dissimilarity analysis (co-phenetic correction coefficient $=0.8121)$ of benthic invertebrate communities at sites in the Speed River in August 2009.

\section{COLUMN FIGURE}




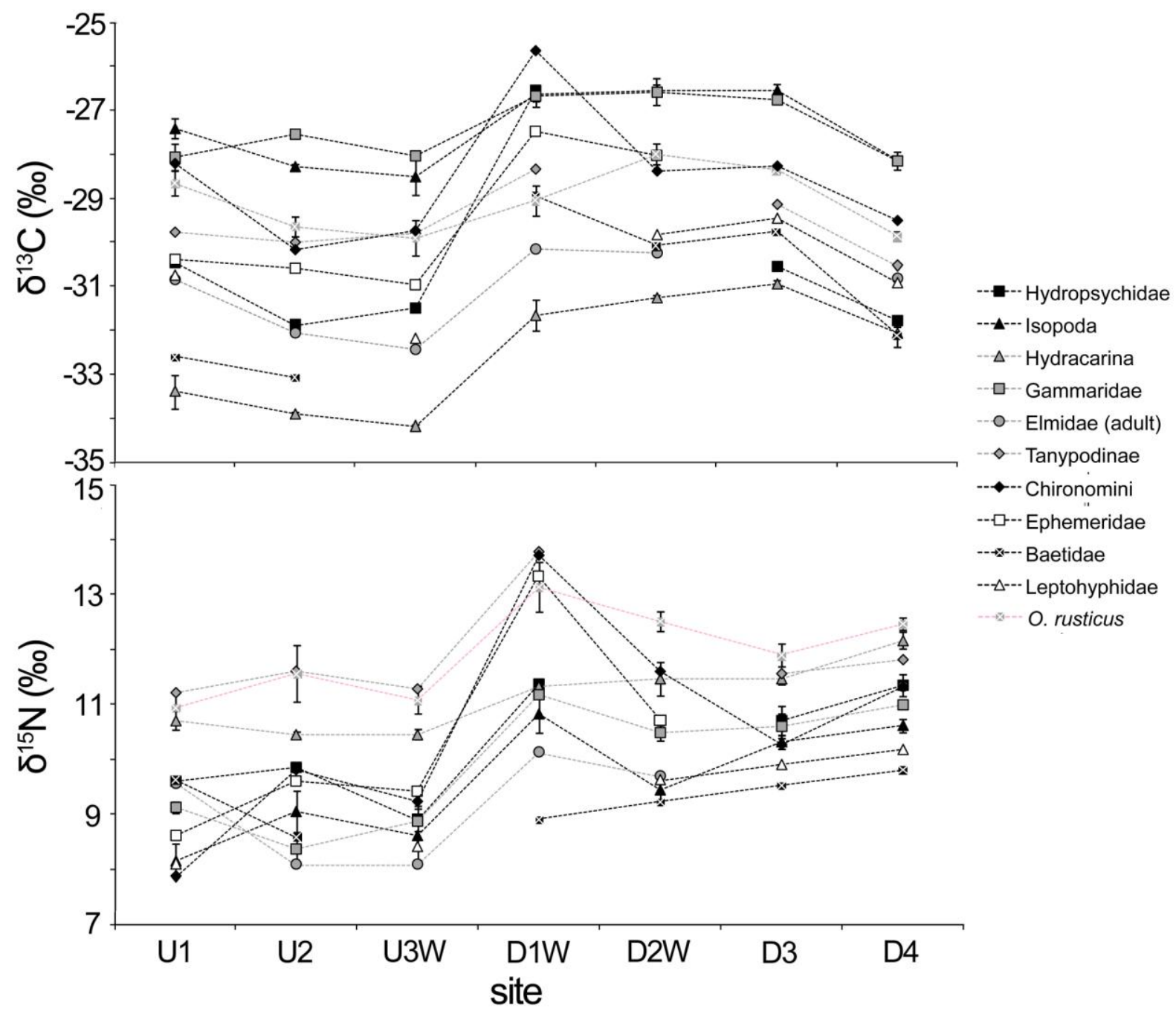

Figure 5. Mean $( \pm \mathrm{SE}) \delta^{13} \mathrm{C}$ and $\delta^{15} \mathrm{~N}$ in benthic invertebrates at sites on the Speed River in August 2009 .

\section{COLUMN FIGURE}



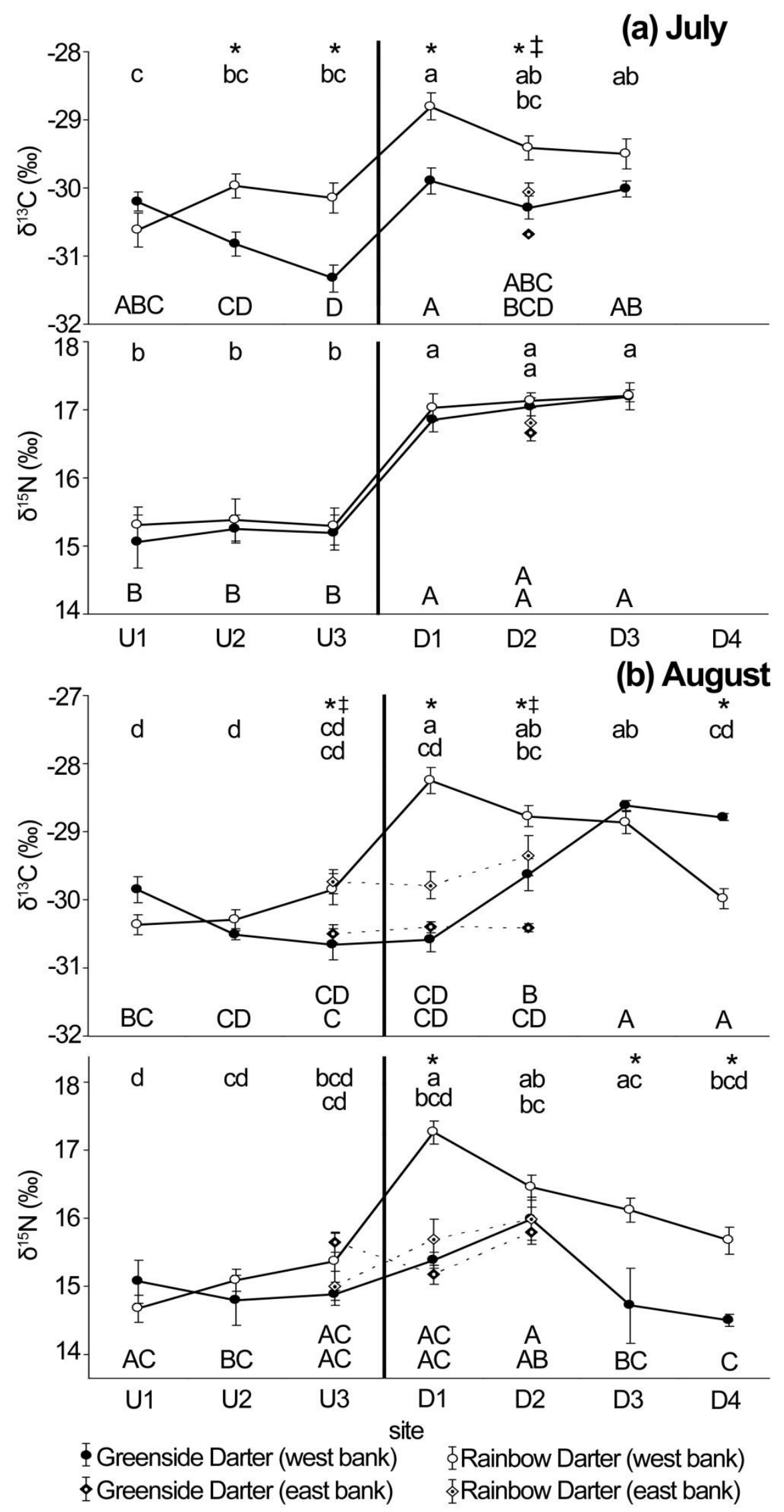
Figure 6. Mean $( \pm \mathrm{SE}) \delta^{13} \mathrm{C}$ and $\delta^{15} \mathrm{~N}$ in muscle of Rainbow and Greenside Darters at sites on the Speed River in (a) August and (b) October. Open circles = Rainbow Darters on west bank, dark circles $=$ Greenside Darters on west bank, open diamonds $=$ Rainbow Darters on east bank, and dark diamonds $=$ Greenside Darters on east bank. An asterik $(*)$ indicates a significant difference $(\mathrm{n}=7-14, \mathrm{p}<0.05)$ between species along the west bank, a double dagger $(\$)$ indicates a significant difference between species along east bank. No fish were collected at D4 in July.

\section{COLUMN FIGURE}




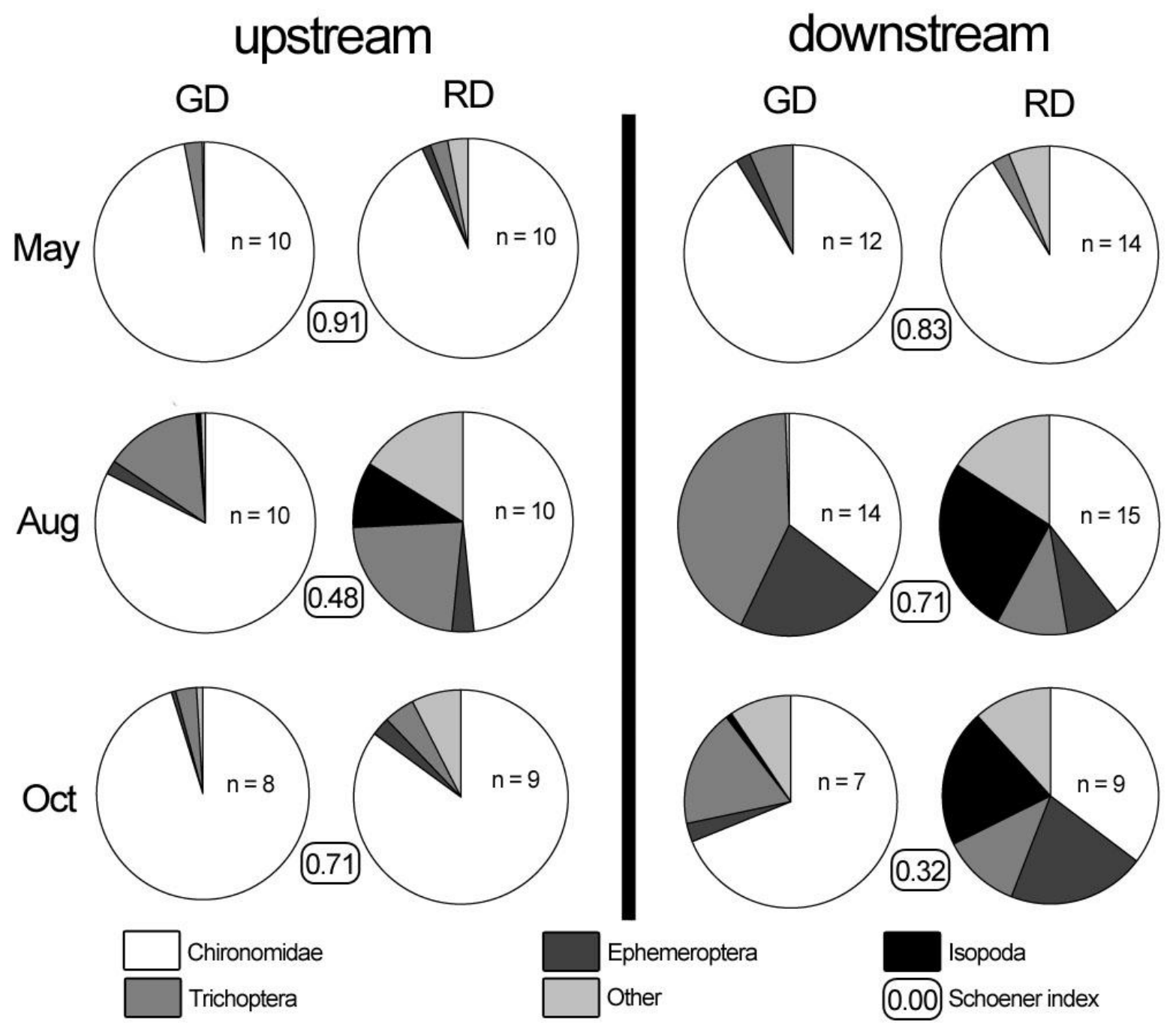

Figure 7. Diet compositions of Greenside (GD) and Rainbow Darters (RD) from immediately upstream (U3W) and downstream (D1W) of the Guelph WWTP in May, August and October 2009. Contents from the fish of the same species were pooled together at each site; n-values indicate the number of fish pooled for each pie graph. Schoener values of percent diet overlap between fish species are presented in between pie graphs.

\subsection{COLUMN FIGURE}


Table 1. Schoener index values for diet overlap between Rainbow and Greenside Darters from May 2009 - March 2010, and the diet overlap between darters of the same species between immediately upstream (US = site U3W) and immediately downstream (DS = site D1W) of the Guelph WWTP from May 2009 - March 2010.

\section{COLUMN TABLE}

\begin{tabular}{ccccccccc}
\hline \multicolumn{10}{c}{ Rainbow vs. Greenside } & \multicolumn{2}{c}{ US vs. DS } \\
\hline Date & U2 & U3W & D1W & D2E & D2W & D3 & GD & RD \\
\hline May & - & 0.93 & 0.86 & - & - & - & 0.91 & 0.83 \\
July & 0.46 & 0.58 & 0.63 & 0.53 & 0.38 & 0.53 & 0.63 & 0.77 \\
August & - & 0.57 & 0.40 & - & - & - & 0.48 & 0.71 \\
October & - & 0.82 & 0.36 & - & - & - & 0.71 & 0.32 \\
March (2010) & - & 0.95 & 0.78 & - & - & - & 0.79 & 0.94 \\
\hline
\end{tabular}

